\title{
0 encontro de Schopenhauer com o pensamento indiano: influência e legitimidade
}

\author{
The encounter of Schopenhauer with Indian thought: influence and \\ legitimacy
}

\author{
Diana Chao Decock \\ Doutoranda em Filosofia pela Universidade de São Paulo (USP) $e$ \\ Professora da Pontifícia Universidade Católica do Paraná (PUCPR) \\ E-mail:decock.diana@gmail.com
}

Resumo: 0 presente artigo tem como objetivo apresentar diferentes posicionamentos sobre o encontro de Schopenhauer com o pensamento indiano. A pergunta sobre a influência e a legitimidade desse encontro é alvo de debate entre indólogos e intérpretes de Schopenhauer e há mais de um século está longe de possibilitar uma única resposta.

Palavras-chave: Schopenhauer; pensamento indiano; influência; legitimidade.
Abstract: This article aims to present differents positions regarding the encounter of Schopenhauer with Indian thought. The issue of the influence and legitimacy of this encounter has been a matter of debate between indologists and Schopenhauer interpreters for over a century, which is far from being resolved by a single answer.

Keywords: Schopenhauer; Indian Thought; Influence; Legitimacy. 
admiração de Schopenhauer pelo pensamento indiano está longe de ser
uma novidade. Não são raras as passagens em que o filósofo expressa
seu enorme apreço às ideias do hinduísmo e do budismo, conduzindo vários pesquisadores a uma investigação assídua sobre as possíveis relações de tais doutrinas com a filosofia schopenhaueriana. Em um percurso que ultrapassa mais de um século de debate, não há, todavia, um consenso sobre a influência e a legitimidade do encontro de Schopenhauer com o pensamento indiano. Porém, encontramos dois posicionamentos recorrentes: um proposto por intérpretes schopenhauerianos e outro por indólogos contemporâneos. 0 primeiro desconsidera a influência do pensamento indiano na filosofia de Schopenhauer, pois o uso de conceitos do hinduísmo présistemático e de práticas do budismo tradicional exprime uma escolha seletiva, cujo objetivo é ilustrar sua própria filosofia. 0 segundo deslegitima a interpretação schopenhaueriana, cuja falta de objetividade promoveu uma visão pessimista do pensamento indiano. Tais posicionamentos, no entanto, negligenciam aspectos fundamentais para a compreensão da filosofia de Schopenhauer, principalmente, no que diz respeito aos interesses do filósofo na incorporação das ideias indianas que, ao nosso ver, não se reduzem a mera justificativa de uma visão pessimista de mundo.

Desde as primeiras publicações de Schopenhauer até os dias atuais a investigação sobre o encontro de Schopenhauer com o pensamento indiano é objeto de análise de vários pesquisadores, inclusive fora do circuito filosófico. Tais análises se divergem principalmente pelo método e pelo material investigado. Curiosamente, após os avanços da indologia, principalmente, no que se refere ao rigor hermenêutico dos textos sagrados, que a legitimidade da interpretação schopenhaueriana passa a ser questionada. Em um primeiro momento, o circuito schopenhaueriano, influenciado especialmente por Paul Deussen, interessa-se mais pelas aproximações entre o pensamento indiano e a filosofia de Schopenhauer do que pela legitimidade interpretativa. Deussen chega até mesmo a elogiar a capacidade interpretativa de Schopenhauer por decifrar a péssima tradução dos Upanixades $^{1}$ feita por AnquetilDuperron$^{2}$. Foram os estudos dos indólogos Helmuth von Glasenapp e Paul Hacker, na segunda metade do século XX, que permitiram, como afirma Douglas Berger, um olhar mais crítico em relação ao entendimento schopenhaueriano da sabedoria indiana. Ao se

\footnotetext{
${ }^{1}$ Utilizaremos o termo Upanixades como transliteração portuguesa da palavra sânscrita Upanishad, presente no Dicionário Houaiss da Língua Portuguesa.

${ }^{2}$ Cf. DEUSSEN, Paul. Wie ich zu Schopenhauer kam, pp. 13-18.

0 encontro de Schopenhauer com o pensamento indiano: influência e legitimidade
} 
debruçarem sobre novas fontes e novos métodos de investigação dos textos sagrados, eles teriam apontado para algumas fraquezas interpretativas. Dentre elas, Schopenhauer teria, segundo Glasenapp, falhado em não distinguir adequadamente tanto o Budismo do Vedanta, quanto a sua própria metafísica da Vontade dos diferentes monismos presentes nos Upanixades. Hacker, por sua vez, teria apontado para a impossibilidade hermenêutica de uma ética baseada na ideia de tat twam asi, até então tomada como a grande "descoberta" schopenhaueriana por grandes intérpretes, inclusive por Glasenapp.

Essas e outras falhas da interpretação de Schopenhauer conduziram à convicção de que o filósofo alemão faz um uso pragmático das ideias indianas com o objetivo de confirmar a sua própria teoria. Por isso, uma grande parte dos intérpretes schopenhauerianos prefere concordar que Schopenhauer primeiramente criou a sua filosofia e só então escolheu os conceitos as ideias indianas que a pudessem justificar. Para Jean Sedler, as anotações sobre o pensamento indiano nos Cadernos de 1814 a 1818 são pequenas e irrisórias, incapazes de comprovar qualquer influência para a elaboração de $O$ mundo como vontade e como representação. Ela acrescenta ainda que os estudos posteriores sobre o budismo, por intermédio de Spence Hardy e Isaac Schmidt, também não teriam interferido nas bases filosóficas de Schopenhauer. A própria noção de negação da vontade foi desenvolvida antes de qualquer conhecimento do pensamento budista, não sendo afetada por qualquer conhecimento posterior ${ }^{3}$. $\mathrm{Na}$ mesma direção encontramos o posicionamento de Christopher Janaway. Para ele, não há evidências cronológicas capazes de atestar a influência do budismo para a formação inicial da filosofia schopenhaueriana. Schopenhauer teria pelo budismo, unicamente, uma gratificação de correspondência. No entanto, o intérprete indica a possibilidade de uma influência dos Upanixades, em especial, da noção de Véu de Maia, para as bases epistemológicas schopenhauerianas, já que tomar o mundo como representação como mera ilusão não poderia ter derivado do pensamento kantiano ${ }^{4}$.

Na apresentação da tradução francesa da obra Quádrupla raiz do princípio de

\footnotetext{
${ }^{3}$ Cf. SEDLER, Jean. India in the mind of Germany: Schelling, Schopenhauer and their times. Washington D.C: University Press of America, 1982.

${ }^{4}$ Douglas Berger, em seu artigo A Question of Influence: Schopenhauer, Early Indian Thought and a Critique of Some Proposed Conditions of Influence, oferece uma discussão detalhada sobre as diferentes posições entre os intérpretes schopenhauerianos sobre a influência do pensamento indiano na filosofia de Schopenhauer.

0 encontro de Schopenhauer com o pensamento indiano: influência e legitimidade
} 
razão suficiente, François-Xavier Chenet e Michel Piclin também apontam para a influência indiana na reelaboração do conceito de representação na construção filosófica de Schopenhauer. Segundo o primeiro, não é possível encontrar nenhuma referência no texto de 1813 sobre o budismo ou brahmanismo, doutrinas que teriam sido apresentadas ao Schopenhauer por Friedrich Mayer. Para Chenet, é "necessário aguardar pelos cadernos de anotações de 1814, que ele cuidadosamente conservou, para encontrar as primeiras alusões ao budismo e pelos escritos de 1816 para reconhecer no Erscheinung kantiano o Véu de Maia"5. Na primeira edição de Quádrupla Raiz, Schopenhauer não mencionaria em nenhum momento, segundo Piclin, que o mundo fenomênico é uma ilusão, sendo essa uma das grandes alterações na edição de 1847.0 intérprete francês chega até mesmo a questionar: Schopenhauer "não transformou o mundo fenomênico do criticismo em um mundo da ilusão, digno dos Vedantas? Ele não confundiu alegremente Erscheinung (aparência) com Schein (ilusão)?"6

Se, por um lado, alguns intérpretes de Schopenhauer reconhecem a influência dos Upanixades para o conceito de representação como mera ilusão, alguns indólogos, por outro lado, questionam a autenticidade dessa influência. Para o indólogo Henry Thomas Colebrooke, somente nas traduções tardias dos Upanixades, e não na doutrina dos textos Vedanta, há a identificação de Maia como ilusão. Traduções como a realizada por Anquetil-Duperron teriam modificado o significado da deusa hindu7. Tal consideração poderia levar à conclusão de que Schopenhauer não teria sido influenciado pelo autêntico pensamento hindu, mas por uma versão deteriorada do intérprete em questão. Por isso, é oportuno ressaltar que Schopenhauer não teria sido influenciado pela sabedoria indiana do séc. VII a. C., mas pelas versões de obras orientais dos séc. XVIII e XIX, fortemente "ocidentalizadas".

Para evitar equívocos sobre por quem de fato Schopenhauer foi influenciado, Urs App se dedica perseverantemente, nas últimas décadas, a evidenciar quando, por quem e por intermédio de qual material ocorreu o encontro de Schopenhauer com o Oriente. Para ele, é necessário se ater aos fatos e às suas sequências históricas antes de qualquer especulação filosófica que se detenha em analisar a influência do pensamento indiano na

\footnotetext{
5 CHENET, F. Présentation. In. SCHOPENHAUER, A. De la quadruple Racine du príncipe de raison suffisan-te, p. 21.

6 PICLIN, M. Avant-Propos, p. 38.

7 Outros indólogos como Arthur Keith e Archibald Gough não concordam com a interpretação de Colebrook. Para eles, nos Upanixades a deusa Maia já era compreendida como ilusão. Sobre este tema conferir a dissertação de Mestrado de Fabio Mesquita "Schopenhauer e o Oriente".

0 encontro de Schopenhauer com o pensamento indiano: influência e legitimidade
} 
filosofia de Schopenhauer. Ao se debruçar sobre os cadernos de anotações, as cartas e os documentos históricos, como, por exemplo, a lista de livros emprestados por Schopenhauer na Biblioteca de Weimar do final de 1813 ao começo de 1814, App demonstra os contatos iniciais de Schopenhauer com o pensamento indiano. As primeiras anotações sobre a Índia fazem referência às aulas do Prof. Schulze, no semestre de inverno de 1810/11 e, principalmente, às do Prof. Heeren, também em 1811, na Universidade de Göttingen. 0 curso ministrado pelo Prof. Heeren sobre a etnografia da Índia tinha como base o periódico Asiatic Researches, editado pelo orientalista Sir William Jones. Porém, o empréstimo dos 9 volumes desse periódico e a sua possível leitura ocorrem só posteriormente, em Dresden, nos anos de 1815 e 1816.

Segundo o intérprete, o primeiro contato do filósofo alemão com os textos sagrados da Índia ocorre em 1813. Após a conclusão de sua tese de doutorado e do encontro com o orientalista Friedrich Mayer, Schopenhauer empresta na biblioteca de Weimar obras que o inserem no universo oriental, a saber, Asiatisches Magazin, em dezembro de 1813, Mythologie des Indous e Oupnek'hat, em março de 1814. A partir de sua investigação, App está ciente de que não há como provar a medida exata da influência dessas obras na elaboração de $O$ mundo como vontade e como representação, mas também julga leviano afirmar que tais conhecimentos não teriam impactado a construção filosófica de Schopenhauer. Pois como o próprio filósofo afirmou, “o orientalista Friedrich Mayer me introduziu, sem a minha solicitação, na antiguidade indiana, e isso teve uma influência essencial sobre mim"8.

As pesquisas de Urs App abriram um novo leque de possibilidades para o estudo de fontes da filosofia schopenhaueriana. A partir da exposição das obras lidas por Schopenhauer no momento anterior à elaboração de sua obra capital, os pesquisadores podem se debruçar sobre esse material a fim de pesquisar com propriedade as reais influências do pensamento indiano na filosofia de Schopenhauer. Segundo o intérprete, Asiatisches Magazin, editada por Julius Klaproth em 1801 e 1802, teria sido a porta de entrada para o conhecimento de Schopenhauer dos textos sagrados. Além de nela haver artigos - 60 no total - dedicados à China, escritos pelo próprio editor, e artigos dedicados à Índia, escritos por Friedrich Mayer, nessa revista também se encontra a versão de

8 SCHOPENHAUER, A. Gesammelte Briefe, p. 261, carta no. 251 a Johann Eduard Erdmann de 9 de abril de 1851.

O encontro de Schopenhauer com o pensamento indiano: influência e legitimidade 
Mayer para o alemão da tradução inglesa de Charles Wilkins de Bhagavad Gita, de 1784. Ao ficar 4 meses com os dois volumes dessa revista, Schopenhauer teria se inserido no universo indiano antes mesmo da leitura de Oupnek'hat. O impacto da leitura de Asiatisches Magazin é visível já em sua primeira publicação de $O$ mundo como vontade $e$ representação, na qual faz referência tanto a Bhagavad Gita ${ }^{9}$, quanto ao artigo Sobre a Foreligião na China, uma versão alemã do texto chinês budista Sutra dos 42 Capítulos, para justificar práticas ascéticas no hinduísmo e no budismo.

No entanto, a leitura que mais impactou Schopenhauer, e com a qual a maior parte dos intérpretes tende a concordar, foi a dos Upanixades, ou, para sermos mais exatos, de Oupnek'hat, a primeira versão ocidental do texto sagrado indiano, cuja tradução para o latim de Anquetil-Duperron deriva da tradução persa realizada pelo Sultão Dara Shikoh, de 1657. Schopenhauer empresta tal obra tanto em Weimar, 4 meses após Asiatisches Magazin, como em Dresden, permanecendo com ela por um período de 8 meses (2 em Weimar e 6 em Dresden). Não são poucas as passagens nas quais Schopenhauer demonstra seu enorme apreço por esta obra, chegando a declarar que ela seria "o mais valioso presente" do seu século10, "a leitura mais gratificante e comovente que pode haver neste mundo", destacando, ainda, que "ela tem sido o consolo da minha vida e será o da minha morte"11.

A partir do levantamento das fontes, fica evidente que o encontro de Schopenhauer com o pensamento indiano ocorre indiretamente na medida em que suas leituras estão subordinadas à interpretação de autores ocidentais, dentre eles, Friedrich Mayer e Anquetil- Duperron. 0 curioso, todavia, é que Schopenhauer não questiona a legitimidade da maior parte de suas fontes, principalmente a de Oupnek'hat, como afirma em Parerga e Paralipomena, no capítulo 16, intitulado Algumas observações sobre a literatura sânscrita:

Por outro lado, considerando que o sultão Mahammed Dara Shikoh, irmão de Aurangzeb, nascido e criado na Índia, ali foi educado, refletiu e esteve desejoso de saber, por isso pude compreender seu sânscrito mais ou menos tão bem como nós compreendemos o nosso latim, já que teve

\footnotetext{
${ }^{9}$ App, em seu artigo Schopenhauer's Initial Encounter with Indian Thought, visa defender que, ao contrário do que a maior parte dos intérpretes afirma, seria a Bhagavad Gita e não os Upanixades o primeiro texto sagrado indiano lido por Schopenhauer; e que tal leitura teria influenciado a sua concepção de mundo como vontade. 10 SCHOPENHAUER, A. MVR I, § 63.

11 SCHOPENHAUER, A. P/P I, § 184.

0 encontro de Schopenhauer com o pensamento indiano: influência e legitimidade
} 
um número dos mais sábios Pandits como colaboradores; tudo isso indica de antemão uma opinião valorosa de sua tradução das Upanishad dos Veda para o persa. Outrossim, vejo com que profunda veneração essa tradução do persa, adequada ao assunto, foi utilizada por AnquetilDuperron ao reproduzi-la palavra por palavra em Latim, mas mantendo a sintaxe persa a despeito da gramática latina, conservando iguais as palavras sânscritas que o Sultão deixou sem traduzir para explicá-las no glossário; assim que leio essa tradução com a mais plena confiança, logo recebe uma lisonjeira aprovação.(...) Tenho a firme convicção de que, até agora, apenas no Oupnekhat é possível conseguir um conhecimento real das Upanishad e, portanto, da dogmática verdadeira e esotérica dos Vedas: pode-se ter lido as demais traduções do princípio ao fim sem ter sequer ideia do tema ${ }^{12}$.

Como podemos observar, Schopenhauer toma a interpretação de AnquetilDuperron fidedigna e acredita que por intermédio dela é possível ter acesso ao real conhecimento dos Veda. Devido a tal julgamento, Schopenhauer é alvo de severas críticas por alguns estudiosos dos textos sagrados indianos, uma vez que ele teve acesso a um material limitado e um tanto quanto questionável. Gestering, por exemplo, acredita que Schopenhauer foi incapaz de compreender a Índia objetivamente, associando a sabedoria indiana ao seu próprio pensamento, enraizado na cultura em que estava inserido. Nesta perspectiva, Schopenhauer seria um etnocêntrico e teria tratado a Índia "como se ela fosse um europeu" sem levar em consideração que a tradição indiana deveria seguir princípios axiológicos inerentes à sua própria cultura. Além de mal interpretar a sabedoria indiana, Gestering critica Schopenhauer por tê-la vinculado ao pensamento pessimista, cuja relação não se justificaria da mesma forma nos textos sagrados.

A crítica ao etnocentrismo e à contaminação do pessimismo se faz presente em várias análises dos indólogos contemporâneos sobre a interpretação de Schopenhauer a respeito do hinduísmo e do budismo. Em India and Europe, Halbfass, ao fazer uma análise cronológica do encontro da Europa com o pensamento indiano, revela que a associação do pensamento schopenhaueriano "com o 'pessimismo' e o 'irracionalismo' não conduziu a apreciação aos mais sutis e ambivalentes elementos da sua abordagem em relação à tradição indiana"13. Por isso, Schopenhauer não é levado tanto em consideração pelos estudiosos indianos, principalmente por aqueles que tentam livrar a

\footnotetext{
12 SCHOPENHAUER, A. P/P, § 184.

13 HALBFASS, W. India and Europe, p. 120.

0 encontro de Schopenhauer com o pensamento indiano: influência e legitimidade
} 
tradição do estigma do pessimismo, como por exemplo Vivekananda e Radhakrishnan ${ }^{14}$.

Embora Schopenhauer tenha estigmatizado o pensamento indiano no ocidente, relacionando-o com o seu próprio pessimismo, como muitos parecem concordar, não podemos negligenciar o fato de que o filósofo alemão também contribuiu, positiva ou negativamente, para a fundamentação de alguns preceitos norteadores do neohinduísmo, o qual, curiosamente, tem Vivekananda como um de seus principais precursores.

No intuito de avaliar a correspondência do neo-hinduísmo com os textos indianos tradicionais, Halbfass, a partir das investigações de Paul Hacker, aponta para a influência ocidental e lamenta o efeito colonizador na religião. E, curiosamente, uma das grandes influências é Schopenhauer. Na obra Philology and Confrontation-Paul Hacker on Traditional and Modern Vedanta, o indólogo demonstra como o contato de Vivekananda com o pensamento schopenhaueriano, principalmente por intermédio de Deussen, foi decisivo para a criação de uma ética hindu, cuja correspondência com os textos tradicionais é um tanto quanto insatisfatória. Antes de seu encontro com Deussen, em 1896, não seria possível encontrar nos escritos de Vivekananda nenhuma menção a tat twam asi, considerada, por Hacker e por Halbfass, como uma ética pseudovedanta. Mesmo na obra Karma-Yoga, de 1895, Vivekananda se ampara no terreno tradicional hindu e compartilha da ideia de que o valor da ação moral está na autoperfeição espiritual. Afinal, "Por que deveríamos fazer bem ao mundo? Aparentemente para fazer bem ao mundo, mas na verdade para ajudar a nós mesmos" e ainda sugere que "devemos desistir desse papo-furado de fazer bem ao mundo [...] devemos trabalhar e constantemente fazer o bem, porque isso é uma benção a nós mesmos"15.

Após o encontro com a filosofia de Schopenhauer, Vivekananda encontra o fundamento da ética tat twam asi e passa a atribuir aos Hindus, em referência a Bhagavad Gita, a descoberta da fundamentação metafísica da ética. Sem levar em consideração a impossibilidade prescritiva de uma ação moral, apontada por Schopenhauer, Vivekananda passa a rejeitar a renúncia e o quietismo em prol de práticas a serviço dos seres humanos. Porém, sua fundamentação tem como base o não dualismo vedanta, que em sua origem não parece ter qualquer pretensão ética. Para Hacker, essa

\footnotetext{
${ }^{14}$ No entanto, não podemos negligenciar o fato de que esses pensadores modernos são pioneiros do neohinduísmo, cuja autenticidade está em avaliação pelos indólogos contemporâneos.

15 VIVEKANANDA, apud HALBFASS, W. Philology and Confrontation-Paul Hacker on Traditional and Modern Vedanta, p. 293.

0 encontro de Schopenhauer com o pensamento indiano: influência e legitimidade
} 
ética não dualista é uma impossibilidade lógica, já que não deixa espaço para a ideia de pessoa, sem o reconhecimento do outro e de relações interpessoais inviável se torna a conduta ética. 0 indólogo ainda conclui que o mal uso da fórmula tat twam asi teria como origem a errônea interpretação de Schopenhauer dos textos sagrados.

Com essa breve exposição, é possível perceber quão conflituoso é o debate acerca da influência e da legitimidade do encontro de Schopenhauer com o pensamento indiano. Embora estejam cientes desse encontro, os intérpretes não parecem concordar ou determinar a medida do impacto na filosofia de Schopenhauer pela influência do pensamento indiano. De fato, algo a ser questionado e impossível de ser negligenciado é a autenticidade dos textos utilizados por Schopenhauer. Como observamos, Schopenhauer teve um acesso indireto aos textos do hinduísmo e do budismo, fazendo uso de traduções e interpretações que ele mesmo não julgava interferir na "real" sabedoria indiana. A falta de um material mais abrangente e talvez mais legítimo, fez com que ele desconsiderasse ou até mesmo mal interpretasse, como afirmam alguns indólogos, conceitos e preceitos da Índia tradicional. Porém, caberia perguntar: a superficialidade de seu conhecimento, assim como seus erros sobre hinduísmo e budismo são suficientes para negar a sua influência? Se levarmos tais justificativas em consideração, poderíamos também questionar o mesmo em relação a Platão e a Kant, visto que Schopenhauer está longe de ser um intérprete fidedigno de tais filósofos ${ }^{16} .0$ uso de leituras ocidentalizadas do pensamento indiano e os sérios erros interpretativos também não parecem ser suficientes para deslegitimar a incorporação dos conceitos e práticas indianas na filosofia de Schopenhauer. Afinal, tais incorporações ofereceram um novo significado não só ao pensamento de Schopenhauer, mas também aos textos sagrados indianos, influenciando, até mesmo, o neo-hinduísmo.

\section{Referências bibliográficas}

\footnotetext{
16 Para Douglas Berger, tanto a falta de um material mais abrangente e legítimo quanto os erros hermenêuticos de Schopenhauer não são suficientes para negar a influência do encontro da sabedoria indiana com o filósofo alemão. 0 próprio uso do pensamento indiano para ilustrar e confirmar a sua própria filosofia seria uma prova dessa influência, pois " a ideia de que Schopenhauer, ou qualquer outra pessoa, pudesse se apropriar de ideias filosóficas sem ter sido influenciado direta ou indiretamente por elas só pode ser considerada uma impossibilidade hermenêutica" (BERGER, D. A question of influence: Schopenhauer, Early Indian Thought and a Critique of Some Proposed Conditions of Influence, p. 113). 
SCHOPENHAUER, Arthur. Sämtliche Werke. Hrsg. von Arthur Hübscher. 7 Bde. Wiesbaden: F. A. Brockhaus, 1972.

. Der Handschriftliche Nachlaß. Hrsg. von Arthur Hübscher. 5 Bde. Frankfurt am Main: Verlag Waldemar Kramer, 1966-1975. . Gesammelte Briefe. Hrsg. von Arthur Hübscher. Bonn: Bouvier, 1987.

. De la quadruple Racine du príncipe de raison suffisante. Librairie Phiposophique J. Vrin, Paris, 1991. 2005. O mundo como vontade e como representação. Tomo I. Trad. Jair Barboza. São Paulo: Unesp, Seis ensaios de Parerga e Paralipomena, pequenos escritos filosóficos. Trad. Rosana Jardim Candeloro. Porto Alegre: Editora Zouk, 2016.

ANQUETIL-DUPERRON (trad.). Oupnek'hat. 1801 (primeiro tomo) e 1802 (segundo tomo).

APP, Urs. Notes and Excerpts by Schopenhauer Related to Volumes 1-9 of the Asiatick Researches. Schopenhauer-Jahrbuch, Bd. 79, 1998, pp. 11-33.

Schopenhauer's India Notes of 1811. Schopenhauer-Jahrbuch, Bd. 87, 2006 pp. 15-31.

_. Schopenhauer's Initial Encounter with Indian Thought. Schopenhauer-Jahrbuch, Bd. 87, 2006, pp. 35-76.

BERGER, Douglas. A question of influence: Schopenhauer, Early Indian Thought and a Critique of Some Proposed Conditions of Influence. In: Schopenhauer and Indian Philosophy: a dialogue between India and Germany. Edited by Arati Barua. New Delhi: Northern Book Centre, 2008, pp. 80-117.

"The Veil of Maya": Schopenhauer's System and Early Indian Thought. Binghamton: Global Academic Publishing, 2004.

CLARKE, J. J. Oriental Enlightenment: The Encounter Between Asian and Western Thought. London-New York: Routledge, 1997.

CROSS, Stephen. Schopenhauer's Encounter with Indian Thought, Representation and Will and their Indian Parallels. Honolulu: University of Hawai'i Press, 2013.

DEUSSEN, Paul. Allegemeine Einleitung und Philosophie des Veda bis auf die Upanishad's. Leipzig: F. A. Brockhaus, 1922.

. Wie ich zu Schopenhauer kam. Schopenhauer-Jahrbuch, Bd. 1, 1912, pp. 13-18.

GESTERING, Johann Joachim. German pessimism and Indian philosophy: a hermeneutic reading. Delhi: Ajanta Publications: Distributors, Ajanta Books International, 1986.

GLASENAPP, Helmuth von. The Influence of Indian Thought on German Philosophy and Literature', Calcutta Review 29, 1928, 203.

GOUGH, Archibald Edward. The Philosophy of the Upanishads and Ancient Indian Metaphysics. $3^{\text {a }}$ ed. London: Kegan Paul, Trench, Trübner \& CO. Ltda., 1903.

HALBFASS, Wilhelm. India and Europe. Motilal Banarsidass Publishers PVT. LTD. Delhi, 1990.

. Philology and Confrontation: Paul Hacker on traditional and Modern Vedanta. Albany, NY:

State University of New York Press, 1995.

HECKER, Max F. Schopenhauer und die indische Philosophie. Köln, 1897.

JANAWAY, Christopher. Schopenhauer - Past Masters (1996). JANAWAY, Christopher (Ed.). The Cambridge Companion to Schopenhauer. Oxford: Cambridge University, 1999.

KEITH, Arthur Berriedale. The Religion and Philosopy of the Veda and Upanishads. Delhi: Motilal Barsidass, 1976.

MOCKRAUER, Franz. Schopenhauer und Indien. Einleitende worte zu den erörterungen über das thema Europa und Indien. Schopenhauer-Jahrbuch, Bd. 15, 1928, pp. 3-26.

NICHOLLS, Moira. The Influences of Eastern Thought on Schopenhauer's Doctrine of the Thingin-Itself. In: The Cambridge Companion to Schopenhauer. Christopher Janaway (Ed.). Cambridge University Press, 1999, pp. 171-212.

SEDLER, Jean. India in the mind of Germany: Schelling, Schopenhauer and their times. Washington D.C: University Press of America, 1982. 
Recebido: 15/10/16 Received: 10/15/16

Aprovado: 14/11/16 Approved: 11/14/16 